\title{
Knowledge and Management Practices of Paediatricians about Autism Spectrum Disorder in Kathmandu, Nepal
}

\author{
Kharti GK${ }^{1}$, Onta SR², Tiwari Suresh ${ }^{3}$, Choulagai BP ${ }^{4}$
}

${ }^{1}$ Ms. Goma Kumari Khatri, MPH, HealthRight International, District Project Office, Kapilvastu, ${ }^{2}$ Prof. Sharad Raj Onta, $\mathrm{PhD}$, Head of Department of Community Medicine and Family Health, Maharajgunj Medical Campus, Maharajgunj, ${ }^{3}$ Dr. Suresh Tiwari, Ph.D., Nepal Health Sector Support Programme (NHSSP), ${ }^{4}$ Dr. Bishnu P Choulagai, MPH, Assistant Professor, Department of Community Medicine and Family Health, Maharajgunj Medical Campus, Maharajgunj.

Address for correspondence: Ms Goma K Khatri, E-mail: shikak2003@gmail.com

\begin{abstract}
Introduction: Autism Spectrum Disorder is increasing day by day around the world. Recent finding of CDC shows that this problem occurs 1 in 110 populations. This problem is such a disorder, which not only affects to the individuals but also the families, society and nation as a whole if not managed properly. Aim: The aim of this study was to assess the knowledge and management practices of Paediatricians about Autism Spectrum Disorder. Methods: The study design was descriptive and cross sectional. A census was used to select the study unit and self-administered questionnaire was used to collect data. Results: Out of 54 Paediatricians, 64.8 percent had inadequet knowledge and 59.3 percent had inadequet practice related to Autism Spectrum Disorder. Majority of them (79.6\%) knew that Autism Spectrum Disorder is a Developmental Disorder but they (24.1\%) also mentioned it to be mental retardation and 13 percent thought that it as a form of psychosis. Most of Paediatricians, (72.2\%) knew that Autism Spectrum Disorder could be due to genetic reason. However, a significant number of respondents 22.2 percent also believed that Autism Spectrum Disorder could occur due to the neglect of children. Almost fifty percent of Paediatricians had rarely handled the Autistic child and a majority of the Paediatricians, $(90.7 \%)$ found it difficult to diagnose this disease. Conclusion: Most of the Paediatricians in Nepal have inadequet knowledge and practice related to Autism Spectrum Disorder. Although some of the practice was good, they also had misconceptions as to managing the children with Autistic disorders. Most of the Paediatricians need to improve their knowledge and practice related to Autism Spectrum Disorder.
\end{abstract}

Key words: Autism Spectrum Disorder (ASD), Autistic, socialisation problem, communication problem, steriotyped behavior.

\section{Introduction}

A utism Spectrum Disorder (ASD) is a group of five disorders, which fall under the pervasive developmental disorders. The five disorders are Autism, Rett syndrome, Childhood Disintegrative Disorder, Asperger Syndrome and Pervasive Developmental Disorder not otherwise specified (usually referred to as PDD-NOS) ${ }^{1}$. It is characterized by impaired social interaction, problems with verbal and nonverbal communication, and unusual, repetitive, or severely limited activities and interests ${ }^{2}$. It has mild to severe forms. In these cases, every Autistic child has distinct features and each of them requires individualized care and support.
Study among $3,551,306$ live births in California in between 1989-1994 showed that 4,381 children were identified with a diagnosis of autism, representing a prevalence of 12.3 per 10,000 live births ${ }^{3}$. Another study showed that 1 in 110 individuals were diagnosed with autism, making it more common than paediatric cancer, diabetes, and AIDS combined in USA ${ }^{4}$. It occurs in all racial, ethnic, and social groups and is four times more likely to strike boys than girls ${ }^{4,5}$.

This problem can be diagnosed as early as 6 months to 18 months of child age ${ }^{1,2}$. However, children are still suffering because of delayed diagnosis and late therapy to modify the behavior with a thought by parents 
and others, that child's development is slow and that he/ she will recover in future. This may happen because of different factors such as inadequate knowledge among the health workers ${ }^{6,7}$, lack of specialized institutions and lack of training to the health workers dealing with this problem $^{8}$. On the other hand, parents may be unaware about this problem.

Parents of Autistic children expect to get good support and care for their child but most of the time they may not be satisfied because of the different forms of advice to the problem of their child from different health professionals. Moreover, they often visit more than one health professional with the hope of getting a satisfactory advice ${ }^{7,8}$. Paediatricians have an important role in early recognition and evaluation of autism spectrum disorders because they are usually the ultimate point of contact for parents. It is essential that paediatricians should be able to recognize the signs and symptoms of ASD and have a competency for assessing them systematically. Moreover, paediatricians have a role in the long term management of this disorder.

This problem may affect any individual anywhere around the world, and is increasing day by day in Nepal too. To our knowledge there hasn't been any study on this problem in Nepal. The objective of this study was to find out the status of knowledge and management practices of paediatricians of our country on this ever growing problem. This would help strengthen the management of children suffering from this disorder.

\section{Methods}

This study was designed to assess the knowledge and management practices of Paediatricians in Kathmandu valley in Nepal. The study design was descriptive and cross sectional. A census was used to select the study unit and self-administered questionnaires were used to collect data. Total respondents were 54 $(87.09 \%)$ of 62 pediatricians available at the time of data collection and currently practicing (mid July to mid August 2009) within Kathmandu valley. Level of knowledge and management practices was determined measuring a set of prior discussed variable according to correct responses given by respondents.

\section{Results}

\section{A. Demographic profile}

Out of 54 respondents, 35 (64.8\%) were males and $19(35.2 \%)$ were females and $20(37 \%)$ had $1-10$ years and $34(63 \%)$ had $10-45$ years of work experiences. Among 54 respondents, $46(85.2 \%)$ had no training and only $8(14.8 \%)$ had training related to ASD. Almost two third 35 (64.8\%) had no experience and 19 (35.2) had some experience related to Autism Spectrum Disorder.

\section{B. Knowledge of Paediatricians}

Almost two thirds $(64.8 \%)$ of paediatricians had less knowledge about Autism Spectrum Disorder. All the respondents $54(100 \%)$ had less knowledge (3 or less than 3 correct answers related to ASD) on the causes.

Among the total responses; $51.8 \%$ responses were for autism 'could be' prevented and $81.5 \%$ responses were for autism 'could be treated'.

\section{Meaning of Autism Spectrum Disorder}

Around 80 percent responses were correct that Autism spectrum Disorder is developmental disorder. However, 55.5 percent responses were incorrect (Table 1).

Table 1: Meaning of Autism Spectrum Disorder (multiple responses).

\begin{tabular}{|l|c|c|}
\hline Descriptions & $\mathbf{n = 6 7}$ & $\mathbf{\%}$ \\
\hline Developmental Disorder & 43 & 79.6 \\
\hline Mental Retardation & 13 & 24.1 \\
\hline Form of Psychosis & 7 & 13.0 \\
\hline Communicable Disease & 4 & 7.4 \\
\hline Total & $\mathbf{6 7}$ & $\mathbf{1 2 4 . 1}$ \\
\hline
\end{tabular}

Level of knowledge identified based on correct options (developmental disorder). Among the 54 respondents, $43(79.6 \%)$ had good knowledge (spelled correct meaning) and 11 (20.4\%) had inadequet knowledge (did not spell correct answer) on meaning of Autism Spectrum Disorder. Although respondents spelled correct response, they also spelled wrong response at the same time giving multiple responses.

\section{Causes of Autism Spectrum Disorder}

$39(72.2 \%)$ responses were for genetic cause, $25(46.3 \%)$ responses for problem in nervous system as causes of Autism Spectrum Disorder. However, 20 $(37 \%)$ responses were wrong or had misconception towards the causes of Autism Spectrum Disorder (Table 2).

Table 2: Causes of Autism Spectrum Disorder (multiple responses)

\begin{tabular}{|l|c|c|}
\hline Descriptions & $\mathbf{n = 8 3}$ & $\mathbf{\%}$ \\
\hline Genetic Cause & 39 & 72.2 \\
\hline Problem in Nervous System & 25 & 46.3 \\
\hline Neglect to the Child & 12 & 22.2 \\
\hline Died Parents & 4 & 7.4 \\
\hline Multi-factorial & 3 & 5.6 \\
\hline Total & $\mathbf{8 3}$ & $\mathbf{1 5 3 . 7}$ \\
\hline
\end{tabular}


Level of knowledge based on correct options were described as: genetic cause, problem in nervous system, health problem during pregnancy, unknown cause, and multi-factorial. Out of all the respondents, $54(100 \%)$ had inadequet knowledge (spelled 3 or less than 3 correct answers) on causes of Autism Spectrum Disorder.

\section{Problem with Socialization}

Out of 153 responses, 51 (94.4\%) responses were for socialization problem described as poor interaction with others. Moreover, $46(85.2 \%)$ responses were for poor eye contact, 32 (59.3\%) responses for loss of attachment, described as a socialization problem of Autism Spectrum Disorder (Table 3).

Table 3: Socialization Problem (multiple responses)

\begin{tabular}{|l|c|c|}
\hline \multicolumn{1}{|c|}{ Descriptions } & $\mathbf{n = 1 5 4}$ & $\mathbf{\%}$ \\
\hline Poor Interaction with Others & 51 & 94.4 \\
\hline Poor Eye Contact & 46 & 85.2 \\
\hline Loss of Attachment & 32 & 59.3 \\
\hline Poor Social Smile & 24 & 44.4 \\
\hline \multicolumn{1}{|c|}{ Total } & $\mathbf{1 5 3}$ & $\mathbf{2 8 3 . 3}$ \\
\hline
\end{tabular}

Level of knowledge identified was based on correct options such as: poor interaction with others, poor eye contact, loss of attachment, cannot understand others feelings, poor social smile. Out of 54 respondents, 27 $(50.0 \%)$ had inadequet knowledge (spelled 3 or less than 3 correct answer) and 27 (50.0\%) had good knowledge (spelled 4-5 correct answers) on the socialization problem of Autism Spectrum Disorder. Although respondents spelled correct response, they also spelled wrong response while giving multiple responses.

\section{Communication Problem}

Majority of the responses were for problem of vocabulary as a communication problem of Autism Spectrum Disorder. Moreover, responses for communication problems described as: 'cannot construct complete sentences' by 31 (57.4\%), 'echolalia' by $31(57.4 \%)$, 'cannot speak even a single word' by $5(9.3 \%)$ which are correct communication problem of Autism Spectrum Disorder. However, some respondents $6(11.1 \%)$ gave wrong responses as per the description of communication problems (Table 4).

Table 4: Communication Problem (multiple responses)

\begin{tabular}{|l|c|c|}
\hline Descriptions & $\mathbf{n = 9 8}$ & $\mathbf{\%}$ \\
\hline Problem of Vocabulary & 34 & 63.0 \\
\hline Cannot Construct Complete Sentences & 31 & 57.4 \\
\hline Echolalia & 31 & 57.4 \\
\hline Poor Attention & 2 & 3.7 \\
\hline Total & $\mathbf{9 8}$ & $\mathbf{1 8 1 . 5}$ \\
\hline
\end{tabular}

Level of knowledge identified based on correct options described as: problem of vocabulary, cannot construct complete sentences, echolalia, cannot speak even single word. Out of 54 respondents 38 $(70.4 \%)$ had inadequet knowledge (spelled 2 or less than 2 right answers) and $16(29.6 \%)$ respondents had good knowledge (spelled 3-4 right answers) on communication problem of Autism Spectrum Disorder. Although respondents spelled correct responses, they also spelled wrong responses at the same time while giving multiple responses.

\section{Stereotyped Behavior}

Out of 189 responses, repetitive action, as a stereotyped behavior got the highest response that is 41 (75.9\%). Moreover, 'special attachment with specific objects' were described by $33(61.1 \%)$, 'sensitive to specific objects/things' by 30 (55.6\%), 'rocking the body' by $29(53.7 \%)$ and 'prefering moving objects' by 11 $(20.4 \%)$ as the stereotyped behavior (Table 5).

Table 5: Stereotyped Behavior (multiple responses)

\begin{tabular}{|c|c|c|}
\hline Descriptions & $\mathbf{n}$ & $\%$ \\
\hline Repetitive Action & 41 & 75.9 \\
\hline Special Attachment with Specific Objects & 33 & 61.1 \\
\hline Sensitive to Specific Objects/Things & 30 & 55.6 \\
\hline Rocking Body & 29 & 53.7 \\
\hline Prefer Moving Objects & 11 & 20.4 \\
\hline Total & 144 & 266.7 \\
\hline
\end{tabular}

Level of knowledge identified based on correct options was described as: repetitive action, special attachments with specific objects/things, sensitive to specific objects/things, rocking body, prefer moving objects, poor sleep. Out of 54 respondents, 37 (68.5\%) had inadequet and 17 (31.5\%) had good knowledge on stereotyped behavior of Autism Spectrum Disorder. Although respondents spelled correct response, they also spelled wrong response at the same time.

\section{Relationship of Independent Variables with Level of Knowledge of Health Workers.}

Education, exposure and training of the Paediatricians have no relationship with level of knowledge about Autism Spectrum Disorder. However, there is a relationship between work experiences and level of knowledge with a $p$-value 0.05 (Table 6).

\section{Management Practices of Health Workers}

Out of 54 respondents, 59.3 had poor practices related to Autism Spectrum Disorder. Among the 83 responses, $31(57.4 \%)$ mentioned that they consulted 
Table 6: Relationship of Independent Variables with Level of Knowledge of Health Workers.

\begin{tabular}{|c|c|c|c|}
\hline & \multicolumn{2}{|c|}{ Level of Knowledge } & \multirow[t]{2}{*}{ Chi -Square Test } \\
\hline & Inadequet & Good & \\
\hline \multicolumn{4}{|l|}{ Education } \\
\hline $\mathrm{DCH} / \mathrm{DMCW}$ & $11(57.9)$ & $8(42.1)$ & $(x 2=1.1, p=0.29)$ \\
\hline MD & $15(42.9)$ & $20(57.1)$ & \\
\hline \multicolumn{4}{|c|}{ Work Experiences } \\
\hline $1-10$ Years & $13(65)$ & $7(35)$ & $(x 2=3.6, p=0.05)$ \\
\hline $11-45$ Years & $13(65)$ & $21(61.8)$ & \\
\hline \multicolumn{4}{|l|}{ Training } \\
\hline No & $23(50)$ & $23(50)$ & $(x 2=0.5, p=0.51)$ \\
\hline Yes & $3(37.5)$ & $5(62.5)$ & \\
\hline \multicolumn{4}{|l|}{ Exposure } \\
\hline No & $16(45.7)$ & $19(54.3)$ & $\left(x^{2}=0.24, p=0.63\right)$ \\
\hline Yes & $10(52.6)$ & $9(47.4)$ & \\
\hline
\end{tabular}

(Note: Figures in parenthesis is in percentage)

DCH: Diploma in Child Health. DMCW: Diploma in Maternal and Child Welfare.

MD: Doctor in Medicine.

colleagues and seniors, $26(48.1 \%)$ mentioned to have consulted literature, 20 (37\%) responses for statement of independent decision while diagnosing the Autistic child.

Out of 67 responses, $28(51.9 \%)$ responses mentioned the problem to separate from co-morbidity and $26(48.1 \%)$ responses for problem of symptoms recognition as the problems while managing the cases. Only $2(3.7 \%)$ responses mentioned not to have any problems while managing the cases.

\section{Management of Socialization}

Out of 136 responses, $44(81.5 \%)$ referred to the specialized personnel/institution, $36(66.7 \%)$ tried to do more by interacting with the child, $28(51.9 \%)$ provided special training to the child and $26(48.1 \%)$ provided special education to the children (Table 7).

Table 7: Management of Socialization Problem (multiple responses)

\begin{tabular}{|l|c|c|}
\hline Descriptions & $\mathbf{n}$ & $\mathbf{\%}$ \\
\hline $\begin{array}{l}\text { Refer to Specialized Personnel/ } \\
\text { Institution }\end{array}$ & 44 & 81.5 \\
\hline Try to do More Interaction with the Child & 36 & 66.7 \\
\hline Provide Special Training to the Child & 28 & 51.9 \\
\hline Provide Special Education to the Child & 26 & 48.1 \\
\hline Total & $\mathbf{1 3 4}$ & $\mathbf{2 4 8 . 2}$ \\
\hline
\end{tabular}

Level of practices identified based on correct statements were described as: refer to special personnel /institutions, try to do more interaction with the child, provide special training to the child, provide special education to the child, and counsel to the parents. Out of 54 respondents, $33(66.7 \%)$ had inadequet practice (spelled 3 or less correct answers) and 18 $(33.3 \%)$ had good practice (spelled 4 or more correct answers) to manage the socialization problem. Although respondents spelled correct response, they also spelled wrong response at the same time.

\section{Management of Communication Problem}

Out of 130 responses, $42(77.8 \%)$ referred to the speech therapist/special institution, $36(66.7 \%)$ tried to interact more with the child, $26(48.1 \%)$ provided special training to the children, $25(46.3 \%)$ provided special education to the caretaker as a metbhod of management of communication problems, which were the right approach. Moreover, $1(1.9 \%)$ response described it as 'cannot manage such problem' (Table 8).

Table 8: Management of Communication Problem (multiple responses)

\begin{tabular}{|c|c|c|}
\hline Descriptions & $n=129$ & $\%$ \\
\hline $\begin{array}{l}\text { Refer to Speech Therapist/Special } \\
\text { Institution }\end{array}$ & 42 & 77.8 \\
\hline Try to do More Interaction with Child & 36 & 66.7 \\
\hline Provide Special Training to the Child & 26 & 48.1 \\
\hline $\begin{array}{l}\text { Provide Special Education to the } \\
\text { Caretaker }\end{array}$ & 25 & 46.3 \\
\hline $\begin{array}{c}\text { Total } \\
\end{array}$ & 129 & 238.9 \\
\hline
\end{tabular}

Level of practices were identified based on correct responses like; refering to speech therapist/special institution, trying to interact more with the child, provide special training to the children, and providing special education to the caretakers. Out of 54 respondents, 27 $(50 \%)$ had good practices (spelled 3 or more correct answers) and 27 (50\%) had inadequet practices (spelled 
2 or less correct answers) to manage communication problems. Although respondents spelled correct response, they also spelled wrong response at the same time.

\section{Management of Stereotyped Behavior}

Out of 112 responses, 40 (74.1\%) referred these children to therapists or concerned institution, 31 (57.4\%) provided special training to the child, 28 (51.9\%) tried to interact more with the child and $1(1.9 \%)$ also did behavior modification with positive or negative feedback as the management of stereotyped behavior, and which were the right approach. However, 4 (7.4\%) responses were for wrong management like managing by isolating the children with stereotyped behavior (Table 9).

Table 9: Management of Stereotyped Behavior (multiple responses)

\begin{tabular}{|l|c|c|}
\hline Descriptions & $\mathbf{n = 1 0 7}$ & $\%$ \\
\hline $\begin{array}{l}\text { Refer to Therapists/Concerned } \\
\text { Institution }\end{array}$ & 40 & 74.1 \\
\hline Provide Special Training to the Child & 31 & 57.4 \\
\hline Try to do More Interaction With Child & 28 & 51.9 \\
\hline $\begin{array}{l}\text { Instruct to the Care Taker to Restrain } \\
\text { the Child }\end{array}$ & 8 & 14.8 \\
\hline Total & $\mathbf{1 0 7}$ & $\mathbf{1 9 8 . 2}$ \\
\hline
\end{tabular}

Level of practices identified was based on correct responses like; refering to therapists/concerned institutions, providing special training to the child, and trying to interact more with the child, behavior modification with positive/negative feedback. Out of 54 respondents, $36(66.7 \%)$ had inadequet practice (spelled 2 or less correct answers) and 18 (33.3\%) had good practice (spelled 3 or more correct answers) to manage stereotyped behavior. Although respondents spelled correct response, they also spelled wrong response at the same time.

\section{Frequency to Handle Autism Spectrum Disorder}

Out of 54 respondents, $28(51.9 \%)$ respondents had rarely handled the cases of Autism Spectrum Disorder, 7 (13\%) respondents had not seen the cases and only $19(35.2 \%)$ respondents handled the Autistic cases (Table 10).

Table 10:Frequency to Handle Autism Spectrum Disorder

\begin{tabular}{|l|c|c|}
\hline Description & $\mathrm{n}=54$ & $\%$ \\
\hline Rarely & 28 & 51.9 \\
\hline Sometimes & 19 & 35.2 \\
\hline Not Yet & 7 & 13.0 \\
\hline \multicolumn{1}{|c|}{ Total } & $\mathbf{5 4}$ & $\mathbf{1 0 0 . 0}$ \\
\hline
\end{tabular}

\section{Feeling of Respondents While Diagnosing Autism Spectrum Disorder}

Majority, $49(90.7 \%)$ respondents felt difficult to diagnose the cases and only 5 (9.3\%) felt comfortable while diagnosing the cases (Table 11).

Table 11: Feelings of Respondents While Diagnosing ASD

\begin{tabular}{|l|c|c|}
\hline Description & $\mathbf{n = 5 4}$ & \% \\
\hline Difficult & 49 & 90.7 \\
\hline Comfortable & 5 & 9.3 \\
\hline Total & 54 & 100.0 \\
\hline
\end{tabular}

\section{E. Relationship of Independent Variables with level of Practices of Health Workers}

There was no relationship of level of practices of pediatricians and their education, work experiences, training and exposure with Autism related activities (Table 12).

Table 12: Relationship of Independent Variables with level of Practices of Health Workers.

\begin{tabular}{|l|c|c|c|}
\hline & \multicolumn{2}{|c|}{ Level of Practices } & \multirow{2}{*}{$\begin{array}{c}\text { Chi } \\
\text { Square } \\
\text { Test }\end{array}$} \\
\hline Inadequet & Good & $\begin{array}{c}(\mathrm{X} 2=2.5 \\
\mathrm{p}=0.11)\end{array}$ \\
\hline Education & $14(73.7)$ & $5(26.3)$ & \\
\hline MD & $18(51.4)$ & $17(48.6)$ & \\
\hline
\end{tabular}

Work Experiences

\begin{tabular}{|l|c|c|c|}
\hline 1-10 Years & $12(60)$ & $8(40)$ & $\begin{array}{c}(x 2=0.00, \\
p=0.93)\end{array}$ \\
\hline 11-45 Years & $20(58.8)$ & $14(41.2)$ & \\
\hline Training & $29(63)$ & $17(37)$ & $\begin{array}{c}(x 2=1.84, \\
p=0.17)\end{array}$ \\
\hline No & $3(37.5)$ & $5(62.5)$ & \\
\hline Yes & $22(62.9)$ & $13(37.1)$ & $\begin{array}{c}(x 2=0.53, \\
p=0.46)\end{array}$ \\
\hline Exposure & $10(52.6)$ & $9(47.4)$ & \\
\hline No & \multicolumn{5}{|l}{} \\
\hline Yes
\end{tabular}

(Note: Figures in parenthesis is in percentage)

DCH: Diploma in Child Health, DMCW:Diploma in Child and Maternal Welfare.

MD: Doctor in Medicine.

\section{Discussions}

This study reflects that majority of the Paediatricians have inadequate knowledge on different aspect of Autism Spectrum Disorder. It shows that 64.8 percent of Paediatricians have inadequet knowledge on Autism Spectrum Disorder. Literature supports the finding that there is lack of awareness and knowledge about the Autism Spectrum disorder among health 
professionals ${ }^{6,9}$. A study of children with Autism in India revealed that among Fifty-one children of Autistic Disorder, Forty-eight (94.2\%) were referred with other diagnoses and correct diagnosis had been made only in $5.8 \%$ of children prior to referral. This reflects the lack of awareness about Autism among medical professionals ${ }^{7}$.

In this study, $24.1 \%$ mentioned that Autism is mental retardation. This finding is correlated with another research finding in which $24.2 \%$ of respondents diagnose the child having symptoms of the Autism as a mental retardation ${ }^{10}$. In that research, frequent comment from professionals was that autism is "very rarely diagnosed and often missed; it is mostly misdiagnosed as mentally retarded"10. This type of notion could have been come from the fact that in $60-70 \%$ cases, Autism had co-morbidity with the Mental Retardation ${ }^{1,2}$.

This study further explored that there is still a misconception (13\%) that Autism is a form of psychosis. This finding is supported by literature that respondents (Primary provider) remain more likely to agree that it is difficult to distinguish autism from childhood schizophrenia ${ }^{9}$. In addition, they were more likely to endorse that children with autism are likely to grow up to be schizophrenic adults ${ }^{9}$. Literature also shows that there are myths related to Autism such as that Autism is a "western disorder" and that the "male Indian child speaks late" as commonly believed in India ${ }^{8}$.

Literature shows that professionals who diagnose autism were primarily psychiatrists and psychologists. Among the diagnoses related to autism, $21 \%$ of diagnoses came from pediatricians and neurologists ${ }^{10}$. The mean age of diagnosis made by the professionals was 58 months and according to parents of autistic child, in approximately $40 \%$ of cases, the professional who made the diagnosis also provided additional information about autism and available resources and spent some time discussing autism with the family. In other cases $(6-34 \%, n=9-50)$, the professionals referred the family to specialists, educational programs, or support groups. However, in $18 \%$ of reported cases $(n=26)$, the professionals provided no additional information beyond the diagnosis ${ }^{11}$. Another study about the concept among professionals about Autism, diagnostic criteria for Autism and background characteristics used by 937 Indian psychiatrists, psychologists and pediatricians were examined. Among them, $80 \%$ of those surveyed noted that diagnosis of Autism is difficult. The study revealed that many professionals perceived Autism as a rare disorder and also revealed that most of them did not consider language disturbances central to the diagnosis of Autism ${ }^{12}$. These literatures correlate with the current research findings that 90.7 percent of health workers find it difficult to diagnose the Autism Spectrum Disorder.

This study also indicated that among the total responses, $51.8 \%$ said that autism could be prevented and $81.5 \%$ also said that autism could be treated. Research shows that about $32 \%$ of the healthcare workers subscribed to the opinion that childhood autism is preventable. About $55 \%$ of the healthcare workers that participated in this study were of the opinion that childhood autism is treatable ${ }^{13}$.

This study showed that there is no association between knowledge and practices with the previous experiences of treating the Autistic child. This could be because they had not had enough exposure in the management of Autistic problems. But some studies also show that opinions of healthcare workers on the treating autism showed significant association with being previously involved with management of children with ASD, with those healthcare workers who have had previous involvement in managing children with ASD more likely to subscribe to the opinion that childhood autism is treatable when compared to those who had not been involved before in the management of children with $\mathrm{ASD}^{14}$.

\section{Conclusion}

Most of the Paediatricians in Nepal have inadequet knowledge and poor practices related to Autism Spectrum Disorder. Although some of the practices were good, they also had misconceptions as to managing the children with Autistic disorders. Most of the Paediatricians need to improve their knowledge and practices related to Autism Spectrum Disorder.

\section{Acknowledgement}

I would like to offer acknowledgement to all of the paediatricians who have actively participated and provided their valuable time. I would also like to thank Maharajgung Campus from where I got such an opportunity. I offer sincere gratitude to Professor Chitra Kumar Gurung, Professor Ramji Prasad Pathak, Associate Professor Amod K. Poudyal, Associate Professor Bandana Pradhan, and Ms Binjwala Shrestha, for their kind support and guidance to accomplish this project.

\section{Conflict of Interest}

This article is based on the final thesis (part of compulsary thesis submission) report submitted to Department of Family Health and Community Medicine Maharjgunj Medical College, Maharajgunj, Tribhuvan University. 


\section{Funding: Nil.}

\section{Permission from IRB: Yes.}

\section{References}

1. American Psychiatric Association. DSM-IV-TR: Diagnostic and Statistical Manual of Mental Disorders, 4th edn text revision. American Psychiatric Association, Washington DC, 2000. ISBN-0890420254 (paperback); ISBN-0890420246 (hardback). http://www.psych.org2005: P. 65-74.

2. WHO. The ICD 10 Classification of Mental and Behavioral Disorders, $10^{\text {th }}$ ed. World Health Association. 1992: P. 252-259.

3. Lisa A. Croen, Judith K. Grether and Steve Selvin. Descriptive Epidemiology of Autism in a California Population: Who Is at Risk? J Autism Dev Disord 2002;32(3):217-24.

4. Autism and Developmental Disabilities Monitoring Network Surveillance, Prevalence of Autism Spectrum Disorders-Autism and Developmental Disabilities Monitoring Network, Six Sites, United States, 2000. Available At: Http://Www.Cdc.Gov/ Ncbddd/Autism/Faq_Prevalence.Htm, Accessed On $20^{\text {th }}$ September 2009.

5. V. Bernard Opitz, K. W. Kwook and S. Sapuan. Epidemiology of Autism in Singapore: Findings of the First Autism Survey. Int $J$ Rehabil Res 2001:24(1):1-6.

6. Krishnamurthy, V. A Clinical Experience of Autism in India. J Dev Behav Pediatr 2008; 29(4):331-3.

7. Juneja, M., S.B. Mukherjee, and S. Sharma. A Descriptive Hospital Based Study of Children with Autism. Indian Pediatr 2005;42(5):453-58.
8. Karande, S. Autism: A Review for Family Physicians. Indian J Med Sci 2006;60(5):205-15.

9. Amanda D. Heidgerken, Gary Geffken, Avani Modi, and Laura Frakey. A Survey of Autism Knowledge in a Health Care Setting. J Autism Dev Disord 2005;35(3):323-30.

10. Tamara C. Daley. From Symptom Recognition to Diagnosis: Children with Autism in Urban India. Soc Sci Med 2004;58(7):1323-325.

11. Rachel A Rhoades, Angela Scarpa and Brenda Salley. The Importance of Physician Knowledge of Autism Spectrum Disorder: Results of a Parent Survey. BMC Pediatr 2007;7:37.

12. Daley, T.C. And M.D. Sigman. Diagnostic Conceptualization of Autism among Indian Psychiatrists, Psychologists, and Pediatricians. J Autism Dev Disord 2002;32(1):13-23.

13. Muideen Owolabi Bakare, Ahamefule O Agomoh, Peter O Ebigbo, Julian Eaton, Kevin O Okonkwo and et al, Etiological Explanation, Treatability and Preventability of Childhood Autism: A Survey of Nigerian Healthcare Workers' Opinion. Ann Gel Psychiatry 2009;8:6.

14. Muideen $O$ Bakare, Peter $O$ Ebigbo, Ahamefule $O$ Agomoh, Julian Eaton, Gabriel M Onyeama And Et Al. Knowledge about Childhood Autism and Opinion Among Healthcare Workers on Availability of Facilities and Law Caring for The Needs and Rights of Children with Childhood Autism and Other Developmental Disorders in Nigeria. BMC Pediatr 2009;9:12.

How to cite this article?

Kharti GK, Onta SR, Tiwari S, Choulagai BP. Knowledge and Management Practices of Paediatricians about Autism Spectrum Disorder in Kathmandu, Nepal. J Nep Paedtr Soc 2011;31(2):98-104. 